\title{
Collaboration in vallue creating networks: the concept of collaborative commerce
}

\author{
Jens ESCHENB $\ddot{A C H E R}{ }^{1}$ and Arian Zwegers ${ }^{2}$ \\ ${ }^{1}$ University of Bremen, Hochschulring 20,28359 Bremen, Germany \\ Email: eb@biba.uni-bremen.de \\ ${ }^{2}$ BAAN, Baron van Nagellstraat 89, 3771 LK Barneveld, Netherlands \\ azwegers@baan.com
}

\begin{abstract}
A new development of e-business/e-commerce is the emphasis on collaboration aspects and collaborative interactions rather than external transactions. The resulting business model has recently been called 'collaborative commerce' or 'c-commerce'. Various studies have shown the large potential of these enterprise strategies. Consequently enterprises will have to adopt approaches such as "collaborative commerce" (or "c-commerce") to remain competitive in most industry segments. C-commerce should be considered a business model rather than a solution that can be offered by vendors. It benefits an enterprise by extending the enterprise's visibility and cooperation throughout the value chain, thereby contributing to the realisation of virtual enterprises. C-commerce requires systems that enable enterprises to share information and collaborate in communities of interest. This paper discusses collaboration in value creating networks and positions and clarifies c-commerce. Some challenges and objectives for the next 3-5 years in c-commerce are presented.
\end{abstract}

\section{Keywords}

Extended products, collaborative commerce, research agenda, value creating networks

\section{INTRODUCTION}

One of the trends in the global market is the fact that enterprises cooperate more extensively with other enterprises during the entire product life cycle. This is related to business drivers, such as the need for cost reduction, flexibility, focus on core competencies, and so on. The result is anything from a rather stable alliance between partners as in a supply chain to a more transitory cooperation as in a Virtual Enterprise. Additionally the development of virtual enterprises has been inspired by electronic business (e-business).

E-business has been acknowledged as major topic for every executive (Deise $e t$ al., 2000; Gloor, 2000). A new development of e-business/e-commerce is emphasis on collaborative aspects and collaborative interactions rather than external transactions. The resulting business model has recently been called 'collaborative commerce' or 'c-commerce'. Recent studies show a large potential for these 
enterprise strategies (Deloitte Consulting, 2001). Enterprises will have to adopt approaches such as 'collaborative commerce' to remain competitive in most industry segments. C-commerce should be considered as a business model rather than a solution that can be offered by vendors. From a conceptual viewpoint, the authors consider c-commerce as a more advanced form of e-business. It benefits an enterprise by extending the enterprise's visibility and cooperation throughout the value chain, thereby contributing to the realisation of virtual enterprises. These cooperations will enable value creating networks to create products and services more efficiently for individual customers. Recently, these products which can be a service or just a utility for the customer have been called 'extended products'.

This paper attempts to provide the reader with a clarification of what ccommerce means. It includes some statements about potential future developments in order to derive some recommendations for future R\&D investments in Europe. There is no doubt that these statements are neither contestable nor they must be correct While the validity of these statements can be contested they provide some key points for discussion about collaboration between enterprises. For this reason, vision statements for collaboration in value creating networks are needed to position c-commerce by taking a conceptual look at ERP II and c-commerce applications. The statements will set out to examine the challenges and objectives for the next 3-5 years in c-commerce.

The paper is organised as follows. Section 2 provides a bit of background about the c-commerce discussion. Firstly, the rationale of the c-commerce evolution is discussed, which is followed by a detailed discussion on the definition of the term itself. The next section discusses the c-commerce vision itself. A discussion on extended products is provided to illustrate the potential of c-commerce. In three subsections, statements about organisational and people related issues, business processes, and applications and technologies are critically analysed which results in a discussion about actions to be taken. The paper concludes with some first outcomes and novel aspects of the research.

\section{BACKGROUND}

\section{Rationale c-commerce evolution}

Nowadays, three major movements put additional requirements on enterprises: globalisation, outsourcing, and increasing customisation. Organisations have expanded their scope to become really global, and have sought to differentiate themselves by excelling at cooperation and collaborative activities. Outsourcing and a focus on core competencies requires better collaboration, synchronisation of processes, and appropriate handling of time and distance constraints. Customisation demands make-to-order manufacturing, better demand visibility, and more flexibility, in general, in order to execute faster and more efficiently. Closer collaboration with partners is required by globalisation, outsourcing, and customisation.

However, the trend towards closer collaboration is hindered by a number of factors. First of all, companies tend to adopt an enterprise-centric perspective. They 
are concerned with their own internal business processes, and pay little attention to inter-enterprise processes. They tend to optimise their own performance, often at the expense of their suppliers. For example, some large car manufacturers have a history of squeezing their suppliers (Frigo-Mosca, 1997).

Popular solutions, which are available in the market today, such as Supply Chain Management (SCM) applications, typically address cooperation within paired relationships. Only the cooperation between an enterprise and its closest suppliers or customers is considered. The supplier's suppliers and the customer's customers are not taken into consideration. Additionally, relationships within supply chains become more and more dynamic in the sense of supply networks (see Figure 1). Although the logistics management of an enterprise towards its direct neighbours might be optimised, the overall supply chain is far from optimal.

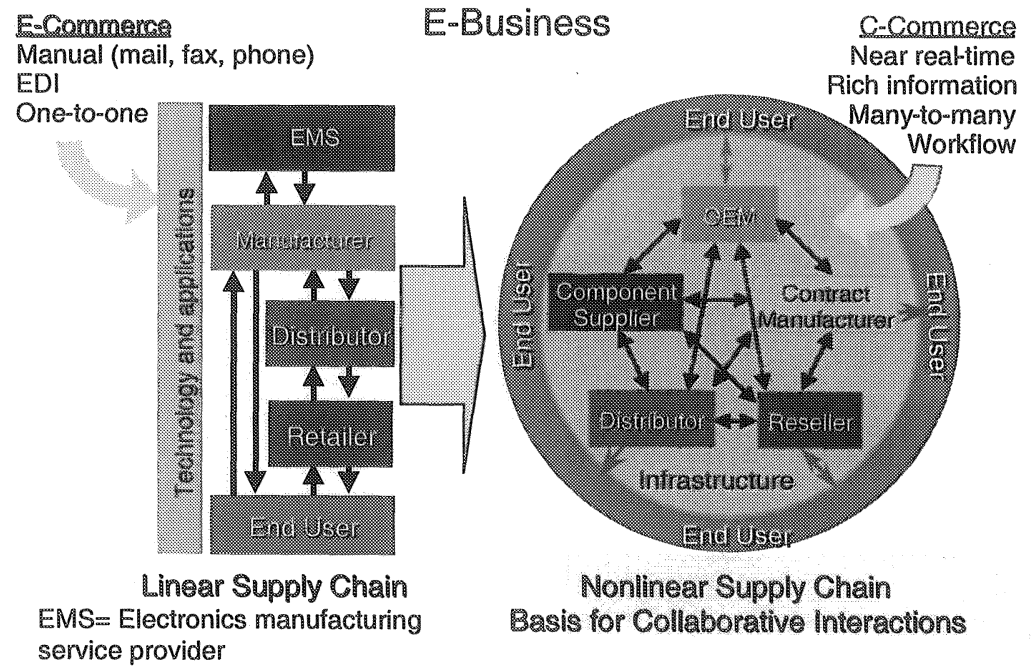

Figure 1: From e-commerce to c-commerce ${ }^{2}$

\section{Definition}

C-Commerce is a term developed by both US market research organisations and consulting companies (see Table 1). Whereas the Gartner definition focuses not only on technical requirements but also on human and organisational issues, the consulting company Morgan Stanley Dean Witter \& Co. and Forrester research prefer a different way of defining the term. Their definition is very much technology oriented and stresses co-operations, which are determined by technology. Consequently, the participants of a network concentrate on their own strengths and profit by themselves from the strengths of all participants in a flexible and dynamic value chain.

\footnotetext{
${ }^{2}$ Adapted from Lora Cecere: Enabling Collaborative Commerce in the Supply Chain. $\mathbb{F} 2000$
} conference 24.5.2000 
Enterprise application solution vendor J.D. Edwards provides its own definition that stresses the inter-organisational business processes alongside the complete supply chain as basis for co-operation. Finally, Mike Carroll of Ingenuus Corp. considers C-Commerce as the next generation of e-business on the way to virtual enterprises. The authors follow the definition of the Gartner Group in the rest of the paper.

Table 1: Definitions of c-Commerce

Forrester Research ${ }^{3}$

C-commerce is a set of standard based portal servers, XML integration servers, that support business processes and is implemented as an architecture. This is captured in a new productization at a process, workflow, and platform level, assimilating the profit, process, and design patterns that enable collaborative interactions between an enterprise, its suppliers, trading partners, customers and employees. Otherwise known as Collaborative Portals. This real-time internet connectivity enables data, intellectual capital, human resources and processes to be shared and used by the collaborative community at large through portals.

Mike Carroll, president and CEO of Ingenuus Corp."

Collaborative commerce, or c-commerce as it is commonly known, is the second generation of e-commerce solutions, providing 10 times the value and power of its predecessor. While e-commerce focuses on cost reduction, c-commerce focuses on new revenue opportunities by bringing more innovative products to market faster than the competition. Collaborative commerce is more than a transaction exchange. It's an intellectual capital exchange that can potentially deliver the much-anticipated virtual enterprise.

Morgan Stanley Dean Witter \& $\mathrm{Co}^{5}$

Collaborative commerce via the Web will spawn a new generation of virtual chains of commerce (integrated demand and supply chains). Ubiquitous and simplified technology will create tightly coupled supply chains that thrive on specialization and flexibility. Functional specialists can concentrate on their link in the supply chain while profiting from recombinant business models to compete with larger, vertically-integrated companies.

\section{J.D.Edwards ${ }^{6}$}

Collaborative Commerce (C-Commerce) describes the internet-based, networked collaboration between all participants of the value chain - from

\footnotetext{
${ }^{3}$ Forrester research, Portals \& Business Transformation, 2001

${ }^{4}$ Carroll, M.. (2001). 'Collaborative Commerce: the next big thing in global manufacturing', EAI Journal, July 2001, p. 20.

${ }^{5}$ http://www.morganstanley.com/institutional/elnterpriseSoftware/B2BReport.html
} 


\begin{tabular}{|l|}
\hline $\begin{array}{l}\text { raw material supplier to the consumer. Inter-organisational, extended } \\
\text { business processes including several partners of a value chain can be seen as } \\
\text { foundation. }\end{array}$ \\
\hline Gartmer Group" \\
"C-commerce, is the set of electronically-enabled collaborative interactions \\
between an enterprise, its suppliers, trading partners, customers and \\
employees. Otherwise known as collaborative commerce, c-commerce \\
leverages the Web to create and maintain an interactive business community \\
of employees, trading partners, suppliers and customers. This real-time \\
Internet connectivity enables data, intellectual capital, human resources and \\
processes that were once considered internal to be shared - and used - by \\
the collaborative community at large."
\end{tabular}

Despite the problems as described in the previous section, it is apparent that enterprises will have to adopt approaches such as 'collaborative commerce' to remain competitive in most industry segments (AMR, 2001; Forrester, 2001; Gartner, 2001). The year 2002 has been suggested by Gartner as the peak in visibility for c-commerce, and the year in which companies start to implement collaborative systems (see Figure 2).

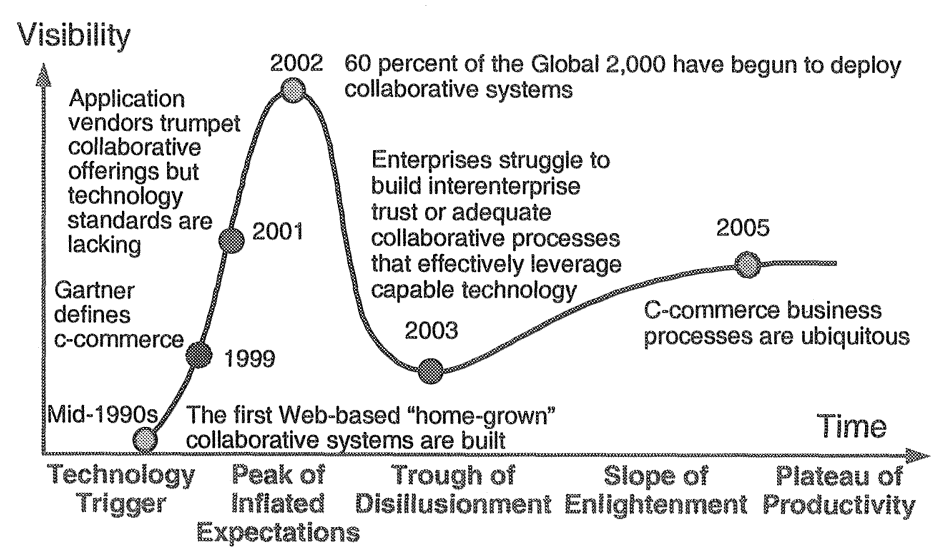

Figure 2: C-Commerce Hype Cycle: A Reality Check (Rayner, 2001)

C-commerce should be considered a business model rather than a solution that can be offered by vendors. It benefits an enterprise by extending the enterprise's visibility and cooperation throughout the value chain, thereby contributing to the realisation of virtual enterprises. A study from Deloitte Consulting shows clearly the

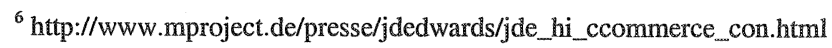

${ }^{7}$ http://www.gartner.com/2_events/conferences_briefings/conferences/spc5_qa.pdf
} 
importance of C-commerce ${ }^{8}$. Perhaps the most essential element of c-commerce is the extension of an enterprise's knowledge assets to include those outside the enterprise. When intellectual capital is leveraged across enterprises, the benefits of c-commerce can be realised. Sharing intellectual capital and combining core competencies with partners are the major ingredients of collaboration.

$\mathrm{C}$-commerce requires systems that enable enterprises to share information and collaborate in communities of interest. The Gartner group sees collaborative marketplaces as a consequence of these developments (see Figure 3).

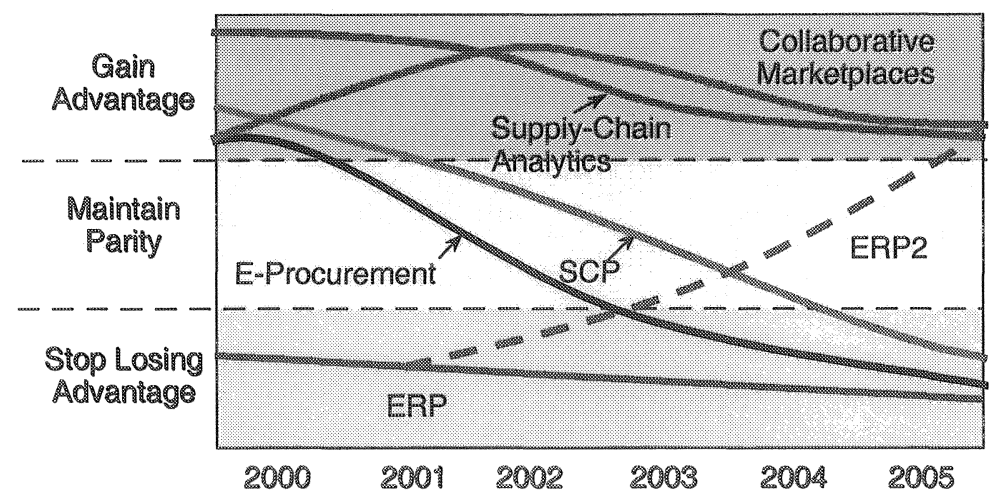

Figure 3: Winning SCM Technologies Short- vs. Long-Term

\section{Role of ERP II}

The next generation of ERP systems, sometimes called "ERP II", and the technologies that support it should provide the flexibility to enable the real-time virtual enterprise through the integration of disparate business systems. The following Table 2, points characterise the differences between ERP and ERP II.

Table 2: Transformation to ERP II (Gartner, 2000)

\begin{tabular}{|c|c|c|}
\hline ERP & $\begin{array}{l}\text { Transformation } \\
\text { step }\end{array}$ & ERP II \\
\hline $\begin{array}{l}\text { Enterprise } \\
\text { optimisation }\end{array}$ & Role & $\begin{array}{l}\text { Value chain participation/ } \\
\text { c-commerce enablement }\end{array}$ \\
\hline $\begin{array}{l}\text { Manufacturing and } \\
\text { distribution }\end{array}$ & Domain & All sectors/segments \\
\hline $\begin{array}{l}\text { Manufacturing, sales } \\
\text { and distribution, and } \\
\text { finance processes }\end{array}$ & Function & $\begin{array}{l}\text { Cross-industry, industry } \\
\text { sector and specific industry } \\
\text { processes }\end{array}$ \\
\hline Internal, hidden & Process & Externally connected \\
\hline Web-aware, closed, & Architecture & Web-based, open, \\
\hline
\end{tabular}

8 Deloitte Consulting: Going public to get private results. Survey about a study published on December 13,2001 on www.dc.com) 


\begin{tabular}{|l|l|l|}
\hline monolithic & & componentised \\
\hline $\begin{array}{c}\text { Internally generated } \\
\text { and consumed }\end{array}$ & Data & $\begin{array}{c}\text { Internally and externally } \\
\text { published / subscribed }\end{array}$ \\
\hline
\end{tabular}

\section{VISION ON C-COMMERCE}

\section{Introduction}

C-Commerce stresses the notion of collaboration within value creating networks. These networks can be more dynamic than the old hierarchical supply chains which did not foresee such an interactive structure without a supply chain leader. In our vision, these value creating partnership networks will be able to provide highly customized products strongly focussing on providing the customer with real benefit instead of a just a product. Hotels such as the Marriott hotel offer their customers a complete business or leisure package which answers all the potential questions the customer might have (Gates, 2000). Recently, these ideas have been discussed as the 'extended product' paradigm in several papers (Thoben et al, 2001; Hirsch and Eschenbächer, 2000).

Extended products, basically products enhanced with additional intangible services, have been identified as new phenomena in industrial engineering. One of the major requirements for their evolution is and was the sufficient support of information and communication technology (ICT). The so-called non-tangible product consists of services, which can be either physical or virtual such as a contract or email. New opportunities and the respective business models raise questions on how to implement such services for the benefit of the customer as well as with affordable costs for the network participants. At this stage, c-commerce and the ongoing discussion on customer-supplier relationship management can provide a platform for extended products. These opportunities can be

w Control of the product along its life cycle.

" New value added services and features.

- Use of intelligent agents (algorithms) to estimate customer wishes.

The concept of the extended product is presented in Figure 4. 


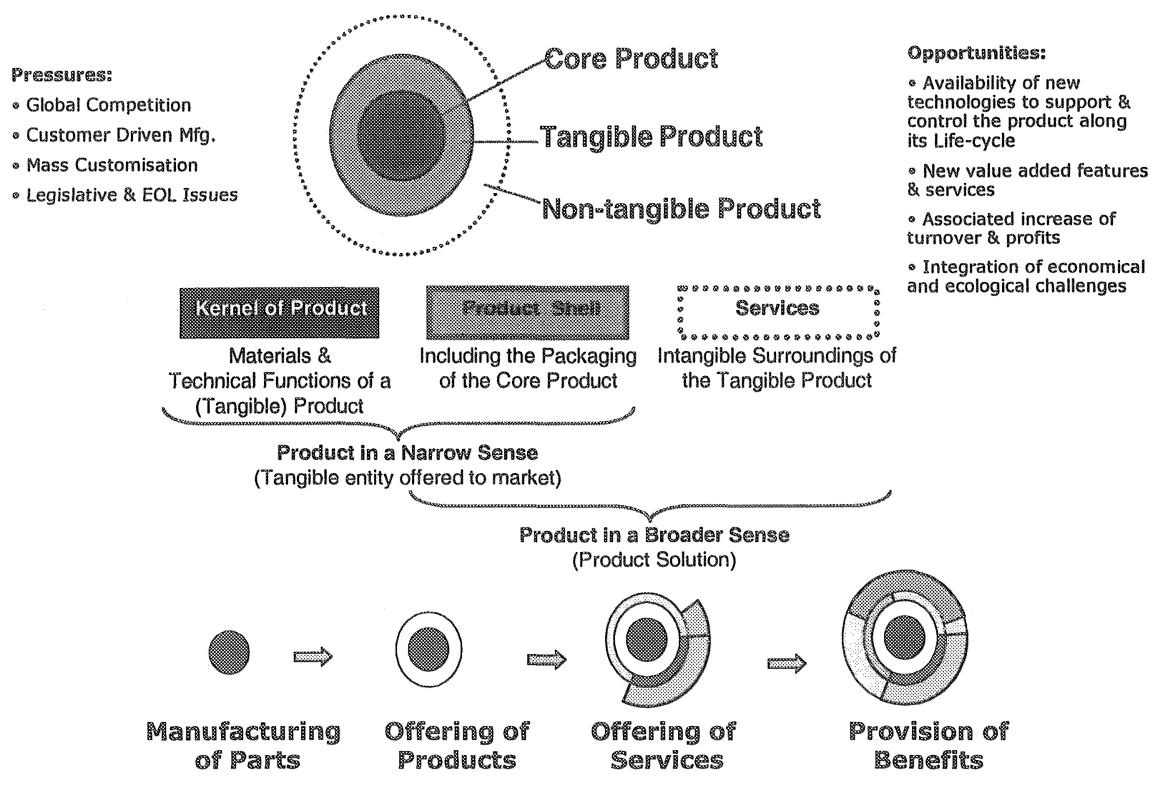

Figure 4: Concept of the extended product

Considering the ideas of extended products in combination with c-commerce, it becomes clear that dynamic value creating networks by nature will be able to fulfil the demands more efficiently than a single enterprise or even extended enterprises. Nevertheless, such a scenario is not implemented yet and customers are still not able to fully customise products. Basically three categories can be stated that must be solved. Before an enterprise can leverage c-commerce for external collaboration, it must have the applications, business processes, and organisational structures internally which can cope with the demands of external transaction processing and collaborative people-to-people interaction. Some issues have to be addressed before an enterprise can be a true c-commerce player. Although these issues are quite interrelated, they can be classified into three main areas:

- organisational issues, including people-related issues,

business processes, and

a applications and technology.

\section{Organisational and people related issues}

Several issues, related to organisations and people, play an important role in the move to c-commerce. Amongst others, enterprises have to establish proper relationships with partners, establish trust among partners, and deal with contract management issues.

Unlike a closed, enterprise-centric supply chain planning situation, in which the constraints are known and resources can be controlled, successful c-commerce initiatives strongly depend upon the development of collaborative relationships. These collaborative processes are focused on streamlining communication between 
supply chain partners, while improving trust and breaking down barriers to sharing information. The so-called "channel masters" control the extended supply chain. They become the natural leaders for development of communication standards and collaborative pilots. Enterprises operating as channel masters can either force channel partners into collaborative business processes, squeezing profitability from trading partners, or develop win/win processes. These enterprises need to act as benevolent dictators, with a focus on the efficiency of the entire supply chain, and establishing proper relationships among its partners that benefit all.

The issue of trust is recognised as an important issue by various authors. For instance, a four-level risk-trust hierarchy was developed by CTP to help enterprises understand and manage the interplay of risk, interdependency, and trust in the networked economy (CTP, 2001). Another four-level model of trust by Sabherwal (1999) has been adopted by Van den Berg and Van Lieshout (2001), who discussed trust in e-commerce and presented measures to increase it.

Operating in such an environment leads enterprises to rethink their way of working regarding contract management. The characteristics of virtual enterprises require enterprises to change their way of working from that of tightly connected legal entities bound together by volumes of contractual documents, to ad hoc casual relationships that are still based on contracts but with a stronger focus on intellectual property protection and valuation. A range of legal issues are beginning to emerge. This is mainly due to the lack of a solid contractual basis to govern the electronic exchange of information and documentation within and between such virtual enterprises. Examples of emerging legal issues are proof of receipt of electronic data (such as drawings and emails), ownership of information, intellectual property and access rights, and company versus project information. EC project eLEGAL (IST1999-20570) addresses these types of issues and aims to define a framework for specifying legal conditions and contracts to enable a legally admissible (exclusive) use of information and communication technology in project business (Hassan et al., 2001). Vendors such as diCarta and I-many already provide commercial contract management solutions.

From an organisational point of view the successful provision of extended products will very much depend on well-adjusted legal and organisational structures. Intangible customer wishes will create an enormous pressure on the value chains to change their organisational behaviour, share more information and to be more open for coopetition rather than competition.

\section{Business processes}

Currently extended products can be seen as one of the main drivers for new business processes (Hirsch et al, 2001). These new business solutions become more and more intangible. Take as an example the mobile phone industry where German customers pay for SMS services. SMS is an intangible messaging service which became a very big success e.g. in logistics and transportation. A collaborating value net will most probably be quicker to make such a new offer reality but mostly such business processes are not well defined yet. (Shuman et al., 2001)

For this reason, it is necessary in c-commerce based relationships to define inter-enterprise business processes, and reference models need to be developed. In 
an enterprise-centric supply chain management situation, the constraints are known and resources are controlled. In a c-commerce environment, however, it is crucial to define and develop collaborative relationships and processes (see Figure 1, right). These inter-enterprise processes are focused on streamlining communication among virtual enterprise partners.

Vendors need to supply solutions that support the business processes in specific industries. They need to provide reference models and supporting technology for inter-enterprise business processes for each industry and perhaps even for different industrial segments.

In addition to the definition of inter-enterprise business processes, workflow management applications are required to manage the execution of these processes. However, different enterprises deal with workflows differently. The way an enterprise processes a sales order might be different from the way another enterprise deals with it. Nevertheless, partners in a virtual enterprise share the responsibility for the execution of inter-enterprise business processes. When enterprises distribute a process among them, the resulting workflow logic could be very conditional. Managing workflows within a virtual enterprise will in general require an eventdriven process rather than a synchronised sequencer.

\section{Applications and technology}

To offer a customer an intangible service is a difficult task considering the technical implications. In former times, it was quite easy to sell the product and ensure e.g. one year guarantee. A utility or intangible benefit can only be provided to a customer if an efficient information and communication system is in place, gathering, analysing and interpreting the customer demands. Therefore, it is a requirement for providing extended products to have systems in place supporting a dynamic exchange of information between the value chain partners.

Indeed this requires new software applications and new technologies. New applications need to provide real-time information and visibility, and need to have a network-centric focus. Figure 5 illustrates an integration infrastructure linking collaborative applications, legacy applications, and packaged applications (such as ERP II) among themselves and with the systems of suppliers, customers, and service providers.

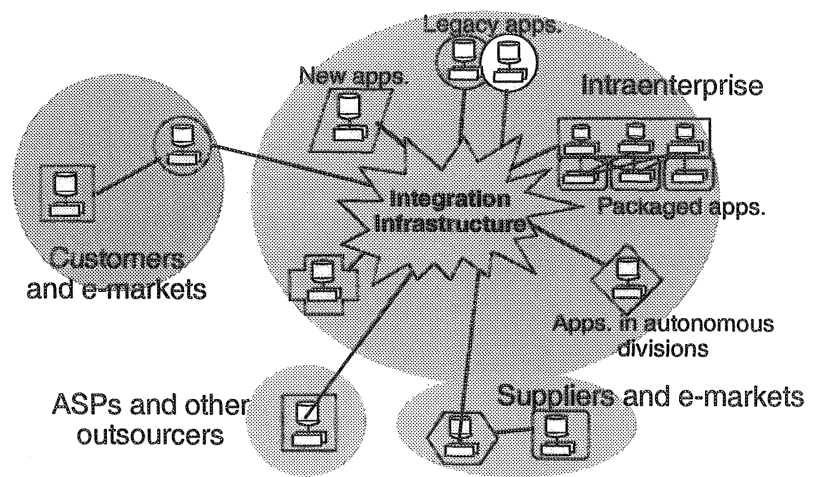

Figure 5: Applications and technologies 
Various collaborative applications are needed to monitor, manage, and optimise the inter-enterprise business processes. Examples of such applications are applications for collaborative project management, collaborative planning, supply chain event management, collaborative product development, extended relationship management, cross-enterprise workflow management, and so on. In order to enhance these applications, a range of new technologies is derived from fields such as distributed artificial intelligence, complexity theory, economics, etc.

Visibility into plant operations is needed for the execution of inter-enterprise business processes. Without that visibility, the synchronisation of production activities in a manufacturing value network can become faulty and misleading. For example, to produce an adequate 'capable-to-promise' statement, visibility into realtime plant capacity based on actual and planned shop floor utilisation is required. Applications need real-time input and processing capabilities. These applications should be capable of real-time event monitoring and handling alerts. Current initiatives in Supply Chain Event Management aim to provide these capabilities and might ultimately realise the Real-Time Enterprise.

The current role of ERP systems will change in a c-commerce environment towards ERP II. Current ERP systems act as the back-office transaction processing systems which focus on enterprise optimisation in a domain which is usually restricted to manufacturing and distribution. In a c-commerce situation, the role of ERP II systems will be to provide the information in such a way that inter-enterprise business processes can be executed and a particular company can participate in a virtual enterprise. ERP systems need to be changed in order to act as a main source of (real-time) information that can be made available to "partners" such as employees, business units, suppliers, and customers. Other applications, such as collaborative planning, collaborative project management, and collaborative product development applications, should use the information supplied by the ERP system to manage and optimise collaboration with partners.

Finally, an integration infrastructure should be able to provide the mechanisms allowing companies to expose internal data to the outside world, to enable interenterprise business processes, and to connect to the various physically distributed legacy applications and systems. Van Busschbach et al. (2002) identify four necessary layers for the integration infrastructure, namely connectivity, transformation, routing, and process management layers.

\section{What needs to be done}

C-Commerce is in its early stage of its development. In contrast e.g. to supply chain management there is no overall theory available which captures all ideas, needs, and visions around this new research paradigm. As a first step the three areas - people and organisational issues, business processes, and applications and infrastructures - need to be carefully analysed. It is indeed quite daring to say that the meaning of competition as driver for wealth and developments shall become reduced because cooperating will be more fruitful than competing against each other. Anyway studies and test industry segments will show whether or not such a vision makes sense. 
Figure 6 summarises the identified challenges related to c-commerce. These challenges have been developed in the IST cluster project EXPIDE (www.expide.org) and represent a very early result of a roadmap analysis about a future research agenda. The final roadmap will update these challenges and indicate the way to achieve these.

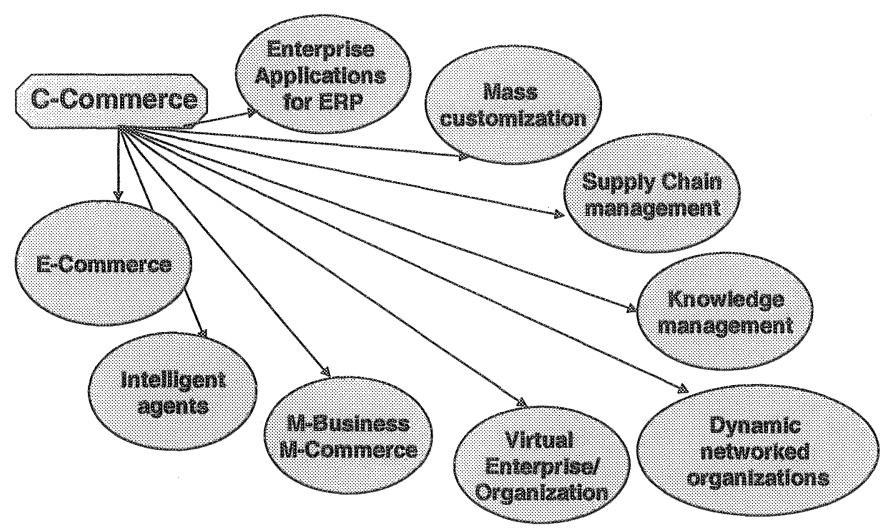

Figure $6:$ Key challenges

The c-commerce paradigm offers a wide range of open research questions and issues which need to be tackled. Without a substantial rethinking of current business processes, it will not be possible to achieve the ambitious objective sketched in Figure 1 of this report.

\section{DISCUSSION}

\section{First outcomes and novel aspects}

This paper describes the initial results of research activities which are still ongoing. The novel aspect and contribution of the work refers to the integration of the ideas of collaborative commerce and the paradigm of extended products. It can be expected that only value creating networks will be able to satisfy the increasing customer demands for intangible benefits. The previous sections have shown the phenomena of c-commerce and the benefits to the evolution of extended products. They can be seen as driver for new products and business processes. Considering the white goods industry - intelligent kitchens - the focus shifts from putting together different machines and furniture towards a complete concept for the kitchen including maintenance and recycling concepts (see Figure 7). Without a doubt, ccommerce will have a major impact on these developments. 


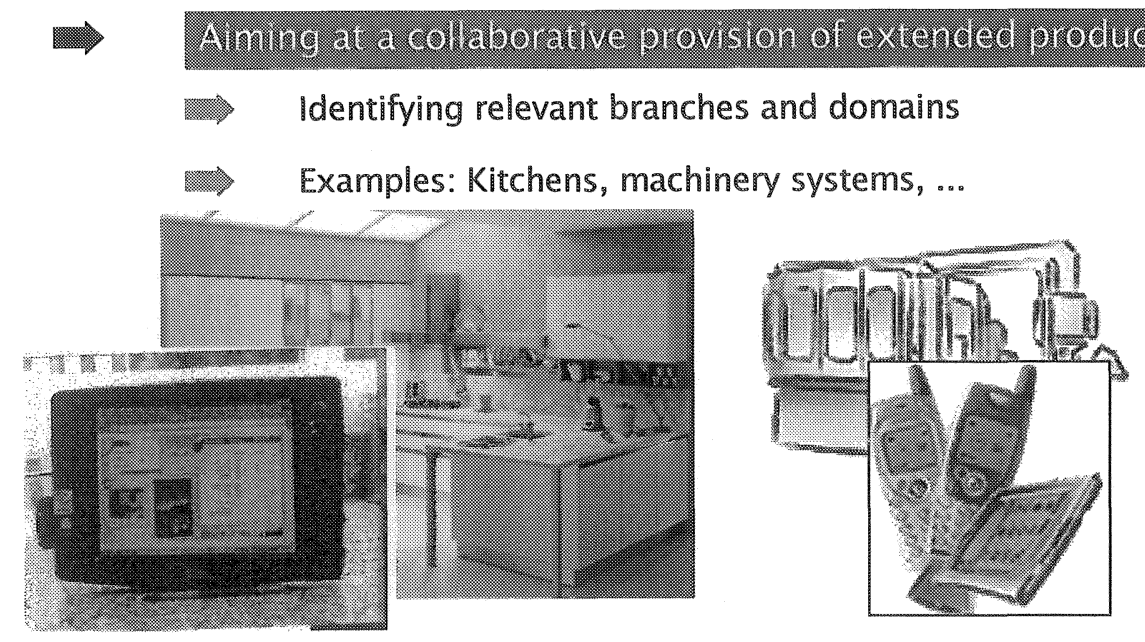

Figure 7: Examples for future extended products

\section{Conclusions and Key Statements}

C-Commerce introduces a wide range of open research questions. All partners of the value chain must sit together to make some of the visionary statements in Section 3 a reality. Leading market research organizations and consultancy firms are dealing with the subject and many of them have set up information sources about $\mathrm{C}$ commerce, e- or m-business or just internet-related enterprise strategies which they publish as newsletters. As key statements the following points can be summarised:

a C-Commerce needs to have a clear concept in order to synthesize industrial needs

a The mentioned topics for people and organisational issues, business processes, and applications and infrastructures in c-commerce need to be tackled by research activities

- Coopetition will replace competition as main driver for innovation

m Case studies must prove the validity of statements provided in this paper

\section{ACKNOWLEDGEMENTS}

This work has been partly funded by the European Commission through IST Project EXPIDE: EXtended Products In Dynamic Enterprises (No. IST-199929105). The authors wish to acknowledge the Commission for their support.

\section{REFERENCES}

[1] Berg RJ van den, Lieshout JM van. Finding symbolons for cyberspace: addressing the issue of trust in elec-tronic commerce. Production Planning and Control 2001; 12 (5): 514-24. 
[2] Busschbach, Erik van, Pieterse, Bram, and Zwegers, Arian. Support of Virtual Enterprises by an Integration Infrastructure. In: Collaborative Business Ecosystems and Virtual Enterprises, Luis Camarinha-Matos (ed.), pp. 311-326. Kluwer Academic Publishers. 2002.

[3] Carroll, M. (2001). 'Collaborative Commerce: the next big thing in global manufacturing', EAI Journal, July 2001, p. 20.

[4] CTP, Cambridge Technology Partners. Various documents on URL: http://www.ctp.com, 2001

[5] Deise, M., Novikow, C., King, P. and Wright (2000). A. Executive's Guide to EBusiness - From Tactics to Strategy. New York: John Wiley \& Sons, Inc.

[6] Deloitte Consulting: Going public to get private results. Survey about a study published on December 13, 2001 on www.dc.com)

[7] Forrester research, Portals \& Business Transformation, 2001.

[8] Frigo-Mosca, Fabio: Referenzmodelle für Supply Chain Management nach den Prinzipen der zwischenbetrieblichen Kooperation, Vdf Hochschulverlag AG at the ETH Zürich, 1997, S. 77

[9] Gates, B. (2000). Business @ the Speed of thought. Warner Books, New York.

[10] Gloor, P. (2000): Making the e-business Transformation. London: Springer-Verlag, Lon-don/Berlin/Heidelberg.

[11] Hassan TM, Carter C, Hannus M, Hyvärinen J. "eLEGAL: Defining a Framework for Legally Admissible Use of ICT in Virtual Enterprises". In Proceedings of the 7th International Conference on Concurrent Enterprising, Bremen, 2001.

[12] Hirsch, B.E., Eschenbächer, J.: Extended Products in Dynamic Enterprises: The IST Project Cluster EXPIDE; in Stanford-Smith, B. und Kidd, P.T. (Hrsg.): E-Business Key Issues Applications Technologies IOS Press; Amsterdam 2000, p. 622-628.

[13] Hirsch, B.-E., Thoben, K.-D., Eschenbächer, J. Using e-business to provide extended products. In: Proceeding of the Automation 2001 in Helsinki from September 4-6, 2001. $492-497$

[14] Hirsch, B.-E., Schumacher, J., Eschenbächer, J. Jansson, K., Ollus, M. and Karvonen, I.: Extended Products: Observatory of current research and development trends in Stanford-Smith, B. and Chiozza, E. (Hrsg.): E-Work and E-Commerce: Novel solutions and practices for a global networked economy 2001, 417-423.

[15] Rayner, Nigel: The Impact Of C-Commerce On ERP Systems. Gartner Symposium Insight of the connected world, March 2001

[16] Sabherwal $R$. The role of trust in outsourced IS development projects. Communications of the ACM; 1999; 42 (2): 80-86.

[17] Shuman, J, Twombly, J., Rottenberg, D. (2001) collaborative communities Partnering for profit in the networked Economy. Dearborn Trade: Chicago.

[18] Software Report, Nr.54 Januar 2001, S.11-13: http://www.softwareag.com/germany/news/soft rep/sw54/SAG Report54 D.pdf

[19] Thoben, K.-D., Jagdev, H. and Eschenbaecher, J.: Extended Products: Evolving Traditional Product concepts. Proceedings of the 7th International Conference on Concurrent Enterprising: Engineering the Knowledge Economy through Cooperation. Bremen Germany, 27-29th June 2001, 429-439.

[20] http://www.morganstanley.com/institutional/elnterpriseSoftware/B2BReport.html

[21] http://www.mproject.de/presse/jdedwards/jde hi ccommerce con.html

[22] http://www.gartner.com/2 events/conferences briefings/conferences/spc5 ga.pdf 